\title{
Enhanced bioavailability of zeaxanthin in a milk-based formulation of wolfberry (Gou Qi Zi; Fructus barbarum L.)
}

\author{
Iris F. F. Benzie ${ }^{1}$, Wai Y. Chung ${ }^{1}$, Junkuan Wang ${ }^{2}$, Myriam Richelle ${ }^{2}$ and Peter Bucheli ${ }^{3}$ \\ ${ }^{1}$ Department of Health Technology and Informatics, The Hong Kong Polytechnic University, Kowloon, Hong Kong \\ ${ }^{2}$ Nestlé Research Center, Lausanne, Switzerland \\ ${ }^{3}$ Nestlé R\&D Center, Shanghai Ltd, Shanghai, China
}

(Received 13 October 2005 - Revised 6 January 2006 - Accepted 22 February 2006)

\begin{abstract}
The carotenoid zeaxanthin is concentrated within the macula. Increased macular zeaxanthin is suggested to lower the risk of age-related macular degeneration. The small red berry, wolfberry (Fructus barbarum L.; Gou Qi Zi and Kei Tze), is one of the richest natural sources of zeaxanthin. However, carotenoid bioavailability is low, and food-based products with enhanced bioavailability are of interest. The present study investigated zeaxanthin bioavailability from three wolfberry formulations. Berries were homogenised in hot $\left(80^{\circ} \mathrm{C}\right)$ water, warm $\left(40^{\circ} \mathrm{C}\right)$ skimmed milk and hot $\left(80^{\circ} \mathrm{C}\right)$ skimmed milk, with freeze drying of each preparation into a powdered form. A zeaxanthin-standardised dose $(15 \mathrm{mg})$ of each was consumed, in randomised order, together with a standardised breakfast by twelve healthy, consenting subjects in a cross-over trial, with a 3-5week washout period between treatments. Blood samples were taken via a venous cannula immediately before (fasting) and 2, 4, 6, 7, 8 and $10 \mathrm{~h}$ post-ingestion. Zeaxanthin concentration in the triacylglycerol-rich lipoprotein fraction of plasma was measured by HPLC. Results showed that triacylglycerol-rich lipoprotein zeaxanthin peaked at $6 \mathrm{~h}$ post-ingestion for all formulations. Zeaxanthin bioavailability from the hot milk formulation was significantly higher $(P<0.001)$ than from the others. Mean area under the curve $(n 12)$ results were 9.73 (SEM 2.45$)$, 3.24 (SEM 0.72) and 3.14 (SEM 1.09) $\mathrm{nmol} \times \mathrm{h} / \mathrm{l}$ for the hot milk, warm milk and hot water formulations, respectively. Results showed clearly that homogenisation of wolfberry in hot skimmed milk results in a formulation that has a 3-fold enhanced bioavailability of zeaxanthin compared with both the 'classical' hot water and warm skimmed milk treatment of the berries.
\end{abstract}

Wolfberry: Kei Tze: Gou Qi Zi: Chinese medicine: Macular degeneration: Zeaxanthin

Zeaxanthin is an oxygenated carotenoid (xanthophyll). Its dietary intake is negatively associated with the incidence of some cancers such as lung cancer (Le Marchand et al. 1993) and colorectal cancer (Slattery et al. 2000) as well as with the progression of early atherosclerosis (Dwyer et al. 2004) or ischaemic stroke (Polidori et al. 2002). Moreover, zeaxanthin also exerts a photoprotective effect both in the skin (Gonzalez et al. 2003) and eye (Rose et al. 1998). This photoprotective effect has been more documented for the eye since zeaxanthin is concentrated within the central area of the macula, or 'yellow spot', of the eye (Landrum \& Bone, 2001). Thinning of the macular pigment accompanies ageing, and is associated with irretrievable loss of central vision (Beatty et al. 1999; Hyman \& Neborsky, 2002). This condition is known as age-related macular degeneration (AMD), and is currently the leading cause of blindness in those aged over 65 years (Stokkermans, 2000; Landrum \& Bone, 2001; Mozaffarieh et al. 2003).

The underlying causes of AMD are not yet clear, but loss of the protective macular pigment is suggested to accelerate oxidative damage to the lipid-rich retina and so increase the risk of AMD (Beatty et al. 2000). There is currently no effective treatment for AMD (Curcio et al. 2000). Therefore, the focus must be on preventing the onset and delaying progression of macular degeneration. It is in this context that dietary carotenoids and their bioavailability are of importance, as it has been suggested that increased intake of carotenoid-rich foods and beverages may be a successful strategy in lowering the risk of AMD (Moeller et al. 2000; Bartlett \& Eperjesi, 2003; Krinsky et al. 2003). Lutein, a structural isomer of zeaxanthin, has been the carotenoid of interest in most studies to date (Landrum et al. 1997; Olmedilla et al. 2001; Bartlett \& Eperjesi, 2003; Bone et al. 2003). However, lutein is found in the peripheral areas of the macula, and zeaxanthin may be of more relevance to AMD prevention owing to its central macular accumulation (Handelman et al. 1988; Landrum et al. 1999; Bone et al. 2000).

In man, both zeaxanthin and lutein are obtained exclusively from the diet. Foods that contain these carotenoids include kiwi fruit, orange juice, melons, spinach, orange pepper and egg yolk (Sommerburg et al. 1998; Benzie, 2003; Humphries \& Khachik, 2003; Weller \& Breithaupt, 2003). Fructus barbarum L., a small red berry known variously as Gou Qi Zi, Kei Tze (Cantonese) and wolfberry, is one of the richest plant sources of

Abbreviations: AMD, age-related macular degeneration; AUC, area under the curve; BHT, butylated hydroxytoluene; IS, internal carotenoid standard; THF, tetrahydrofuran.

* Corresponding author: Professor Iris Benzie, fax + 852 23624365, email iris.benzie@inet.polyu.edu.hk 
zeaxanthin (Lam \& But, 1999; Zhou et al. 1999; Weller \& Breithaupt, 2003, Cheng et al. 2005). Wolfberry from Ningxia province is commonly used in China in soups, tea, drinks, hot pots, supplements and others. Wolfberry has a strong reputation in Chinese culture as being beneficial for vision, as well as being regarded as an anti-ageing traditional medicine that addresses Yin deficiencies of liver and kidney, a condition that is associated with diabetes in Chinese medicine (Bai, 1999; Lam \& But, 1999; Cheng et al. 2005). Wolfberries are usually purchased in a semi-dried form and are similar in size and texture to a raisin. Although high, the zeaxanthin content of dried wolfberries varies widely, with values reported as $11.5-43 \cdot 3 \mu \mathrm{g} / \mathrm{g}$ (Lam \& But, 1999), $194 \mu \mathrm{g} / \mathrm{g}$ (Cheng et al. 2005), $300 \mu \mathrm{g} / \mathrm{g}$ (Leung et al. 2001) and $820 \mu \mathrm{g} / \mathrm{g}$ (Weller \& Breithaupt, 2003). In comparison, spinach, maize and squash generally contain $<3 \mu \mathrm{g} / \mathrm{g}$ (Sommerburg et al. 1998; Humphries \& Khachik, 2003). The wide variation in zeaxanthin content of wolfberry is probably caused by different growing, drying and storage conditions, as well as intrinsic differences in quality of the berries and perhaps differences in methods used for measurement of zeaxanthin.

Zeaxanthin is lipophilic and most zeaxanthin in foods, including wolfberry, is in the dipalmitate ester form (Zhou et al. 1999; Weller \& Breithaupt, 2003). However, xanthophyll esters are hydrolysed during the digestive process, and newly absorbed zeaxanthin is incorporated within the chylomicron component of triacylglycerol-rich lipoproteins (Pérez-Gálvez et al. 2003). Therefore, in assessing bioavailability of dietary zeaxanthin, studying the post-ingestion response in terms of the zeaxanthin content of triacylglycerol-rich lipoproteins harvested from plasma is an appropriate approach, and is preferable to measuring post-ingestion changes in whole plasma zeaxanthin concentration. This lipoprotein content approach can also be used to compare the bioavailability of zeaxanthin in different foods or food extracts, and to evaluate carotenoid-containing formulations designed to have enhanced bioavailability.

Therefore, the aim of the present study was to compare the bioavailability of zeaxanthin in different wolfberry-based formulations in a human intervention trial. Two formulations were milk-based, the difference between them being the temperature at which homogenisation of the berries was carried out. The third emulated the 'classical' hot water treatment of the berries and this acted as the control treatment.

\section{Materials and methods}

The present study was a double-blinded, controlled, human intervention trial of multiple cross-over design. The study was granted ethical approval by The Hong Kong Polytechnic University (Kowloon, Hong Kong). All subjects gave written informed consent, and all procedures involving human subjects complied with the Declaration of Helsinki as revised in 2000. Subject recruitment, intervention, sample collection and laboratory work were all performed at The Hong Kong Polytechnic University.

\section{Subjects}

Recruitment of subjects was by poster and word of mouth. A total of nineteen subjects volunteered for the study. In pre-study testing, fasting plasma lipids, plasma glucose, blood $\mathrm{Hb}$, blood pressure, pulse rate, weight and height were measured. Sixteen subjects met all our inclusion criteria, which were as follows: no evidence of diabetes; hyperlipidaemia or anaemia; not obese or overweight; non-smoker; not hypertensive; not a regular user of food supplements or aspirin; no history of serious or chronic disease. In the early stages of the study, four subjects withdrew for personal reasons or because of difficulty in drawing blood. Twelve subjects (seven women (all non-pregnant throughout the trial) and five men) completed the study. All subjects were Chinese, in good general health and aged between 21 and 30 years of age.

To minimise the drop-out rate, volunteers were carefully counselled on the details and frequency of the sample collection. Subjects were contacted by email and phone at least weekly between treatments, and were contacted the day before each treatment. On study days the subjects were closely supervised to ensure their welfare and to facilitate their continued participation.

\section{Study design}

All twelve subjects took all three zeaxanthin-containing formulations (designated as treatments A, B and C). Each treatment was taken on a separate day. The elimination half-life of zeaxanthin in plasma has been estimated to be about $14 \mathrm{~d}$ (Hartmann et al. 2004). Therefore, each treatment day for each subject was at least 3 weeks (but no more than 5 weeks) apart in order to avoid treatment carry-over effects. The order of treatment for each subject was arranged according to a William's latin square to ensure against an order effect. Each zeaxanthin treatment was given in conjunction with a standard, fat-containing breakfast to facilitate absorption.

\section{Treatments}

The A, B and C wolfberry formulations were supplied by Nestlé Research Center (Lausanne, Switzerland), and were provided in labelled (as A, B or C), sealed aluminium foil sachets, each containing a single, pre-weighed dose of powder containing the same amount $(15 \mathrm{mg})$ of zeaxanthin. Formulation A contained wolfberries that had been homogenised in skimmed milk at $80^{\circ} \mathrm{C}$; formulation B contained wolfberries that had been homogenised in skimmed milk at $40^{\circ} \mathrm{C}$; formulation $\mathrm{C}$ contained wolfberries that had been ground and heated in water at $80^{\circ} \mathrm{C}$. All berries used in the preparation of these formulations were from the same batch produced in Ningxia Province, China in summer 2003. On study days, the appropriate sachets were opened and the entire contents of one sachet were mixed with the rice porridge part of a standard meal, which was then served and eaten within $10 \mathrm{~min}$. The meal was prepared as follows: $50 \mathrm{~g}$ dehydrated rice flakes (LongDi Co, Shenyang, China) were mixed with $250 \mathrm{ml}$ hot water to which $10 \mathrm{~g}$ groundnut oil (Knife Brand pure groundnut oil; Lam Soon, Hong Kong; the same batch of oil was used throughout the study, but a newly opened bottle was used each time) and $12 \mathrm{ml}$ liquid seasoning (Maggi Dongguan Ltd, China) were added, with the same bottle of seasoning used throughout the study. The appropriate pre-weighed powder constituting treatment $\mathrm{A}, \mathrm{B}$ or $\mathrm{C}$ was then mixed with the rice porridge, and the meal was served immediately thereafter and eaten within $10 \mathrm{~min}$. One standard 
slice of white bread (purchased from a local shop) and a cup $(200 \mathrm{ml})$ of warm water were also served. Volunteers were instructed to use the bread to mop up all remaining liquid in the bowl after the rice porridge had been eaten. No other food or drink (except water, which was allowed in unlimited amounts) was allowed until after the $10 \mathrm{~h}$ post-ingestion blood sample was collected.

\section{Blinding}

Treatments and subjects were coded. Volunteers and the members of the project team collecting and processing the blood samples were blinded to the identity of each treatment. Furthermore, the project personnel performing the laboratory and data analyses were blinded as to which treatment (A, B or C) was given on each treatment day.

\section{Procedure on each study day}

Subjects were requested to arrive fasting. For each subject, an in-dwelling venous cannula was fitted and a fasting venous blood sample was collected into commercial EDTA blood collection tubes. This was designated the ' 0 ' time sample. A freshly prepared standard meal containing $15 \mathrm{mg}$ zeaxanthin in one of the three formulations was then served to each subject, and this was eaten within $10 \mathrm{~min}$. Additional blood samples were collected at 2, 4, 6, 7, 8 and $10 \mathrm{~h}$ post-ingestion, via the in-dwelling cannula. After collection, blood samples were immediately placed in the dark and at $4^{\circ} \mathrm{C}$. In conditions of dim light, plasma was separated from cells after centrifugation $\left(4^{\circ} \mathrm{C}, 10 \mathrm{~min}\right.$ at $\left.1000 \mathrm{~g}\right)$. EDTA plasma was sampled and immediately placed at $-80^{\circ} \mathrm{C}$ for storage for later harvesting of the triacylglycerol-rich fraction and zeaxanthin measurement. Subjects were closely supervised during each study day in order to ensure they ate all the breakfast, that they did not eat anything else, and to check their wellbeing. After the $10 \mathrm{~h}$ blood sample was collected and the cannula removed, the subjects were provided with a meal and a soft drink.

\section{Harvesting of triacylglycerol-rich lipoproteins for zeaxanthin measurement}

The extraction of the triacylglycerol-rich fraction from EDTA plasma was modified from the method performed by Terpstra (1985). Samples were processed in sets; each set comprised all seven plasma samples ( 0 time, $2,4,6,7,8,10 \mathrm{~h}$ post-ingestion) for one treatment for one subject. For harvesting of the triacylglycerol-rich fraction, freshly thawed EDTA plasma $(2 \mathrm{ml})$ was mixed gently with $\mathrm{KBr}(450 \mathrm{mg})$, sucrose $(50 \mathrm{mg})$ and ethylene glycol $(200 \mu \mathrm{l})$. The mixture was then overlaid sequentially with $500 \mu \mathrm{l} \mathrm{KBr}(1.225 \mathrm{~kg} / \mathrm{l}), 500 \mu \mathrm{KBr}$ $(1 \cdot 100 \mathrm{~kg} / \mathrm{l})$ and $1300 \mu \mathrm{l}$ Milli-Q water in an OptiSeal tube. As much as possible of the triacylglycerol-rich fraction (the top layer, and representing the triacylglycerol-rich fraction of $2 \mathrm{ml}$ plasma) was isolated after ultracentrifugation at 49 $000 \mathrm{~g}, 20^{\circ} \mathrm{C}$ for $15 \mathrm{~min}$ (Beckman Ultracentrifuge with rotor TLA 100.4; Beckman Coulter, Inc., Fullerton, CA, USA).

Zeaxanthin was measured by a reverse-phase HPLC technique and employing a UV detection system. Reagents were as follows: the zeaxanthin calibrator was purchased from
Indofine Chemical Company Inc. (Hillsborough, NJ, USA); the internal carotenoid standard (IS) was from Chromsystems Instruments and Chemicals $\mathrm{GmbH}$ (Munich, Germany); methanol, absolute ethanol, tetrahydrofuran (THF) and hexane (all Chromosolve for HPLC) were from Riedel-de Haen (Sigma-Aldrich Laborchemikalien GmbH, Seelze, Germany); butylated hydroxytoluene (BHT), ethylene glycol, sucrose, $\mathrm{KBr}$ and ethylene-diamine tetraacetic acid di-sodium dihydrate (EDTA- $\mathrm{Na}_{2} \cdot 2 \mathrm{H}_{2} \mathrm{O}$ ) were from Sigma (St Louis, MO, USA); ascorbic acid and $\alpha$-tocopherol were from E. Merck (Darmstadt, Germany); acetonitrile (HiperSolv for HPLC) was from BDH Laboratory Supplies (Poole, Dorset, UK). The tubes for ultracentrifugation, OptiSeal tubes (capacity $4.7 \mathrm{ml}$ ), were obtained from Beckman Coulter, Inc. Falcon polypropylene tubes $(15 \mathrm{ml}, 17 \times 120 \mathrm{~mm}$, with screwed cap) for extraction were from Becton Dickinson and Company (Franklin Lakes, NJ, USA). Milli-Q water was made with a Millipore ultra-pure water system (Millipore Corp., Bedford, MA, USA).

For calibration, a stock solution $(879.0 \mu \mathrm{mol} / \mathrm{l})$ of zeaxanthin was first prepared in $0.1 \%(\mathrm{w} / \mathrm{v})$ BHT-THF containing $\alpha$-tocopherol $(8.8 \mathrm{mmol} / \mathrm{l})$. With dilutions (in $0.1 \%(\mathrm{w} / \mathrm{v})$ BHT-ethanol) of this stock solution, a working solution containing zeaxanthin $(17.6 \mu \mathrm{mol} / \mathrm{l})$ was made up in $0.1 \%(\mathrm{w} / \mathrm{v})$ BHT-ethanol containing $\alpha$-tocopherol $(1 \mathrm{mmol} / \mathrm{l})$. A working solution of IS was made by diluting 1:25 $(\mathrm{v} / \mathrm{v})$ of original IS solution with $0 \cdot 1 \%(\mathrm{w} / \mathrm{v})$ BHT-ethanol.

\section{Preparation of calibrators, pooled plasma and controls}

All preparations involving BHT and THF were made freshly as needed. Strong light was avoided during preparations of calibrators and samples. From the working solution of zeaxanthin $(17.6 \mu \mathrm{mol} / \mathrm{l})$, various concentrations of zeaxanthin $(0-0 \cdot 211 \mu \mathrm{mol} / \mathrm{l})$ were freshly and serially diluted with Diluent 1, which was a solution of 20:80 (v/v) of $0.1 \%(\mathrm{w} / \mathrm{v})$ BHT-THF to Diluent $(1: 20(\mathrm{v} / \mathrm{v})$ of $0.1 \% \mathrm{w} / \mathrm{v}$ aqueous EDTA- $\mathrm{Na}_{2} \cdot 2 \mathrm{H}_{2} \mathrm{O}$ to mobile phase, the solution filtered through a $0.22 \mu \mathrm{m}$ Millipore membrane). By spiking suitable amounts of each prepared zeaxanthin solution together with IS working solution $(100 \mu 1)$ into Milli-Q water, these final solutions, referred to calibrators, were used to construct the calibration curve.

The pooled plasma for controls was obtained from healthy human subjects. Venous blood from the antecubital vein of consenting volunteers was collected into commercially available heparinised tubes, chilled in ice-water and kept in the dark until plasma was separated from cells. Separation of plasma from blood was performed by centrifugation at $2500 \mathrm{~g}, 4{ }^{\circ} \mathrm{C}$, for $10 \mathrm{~min}$. Some of this was sampled and stored at $-80^{\circ} \mathrm{C}$ and was used as a 'normal' plasma control. The rest was used to prepare a 'high' plasma control: zeaxanthin was spiked into this plasma, which was then sampled and stored at $-80^{\circ} \mathrm{C}$.

For extraction of zeaxanthin in calibrators, triacylglycerolrich fractions and plasma controls, the extraction procedure was based on that of Aebischer et al. (1999). A $100 \mu l$ sample of the diluted zeaxanthin working solution was first mixed in a Falcon tube with $500 \mu \mathrm{l}$ Milli-Q water containing $100 \mu \mathrm{l} \quad 0.1 \% \quad(\mathrm{w} / \mathrm{v})$ aqueous ascorbic acid. To this solution, $100 \mu \mathrm{l}$ IS working solution was added and mixed, 
followed by the addition of $300 \mu$ l ethanol. The mixture was again hand-shaken to mix and $1000 \mu$ l hexane containing BHT (a $0.1 \%(\mathrm{w} / \mathrm{v})$ solution) was added. The tube containing the mixture was rolled for $30 \mathrm{~min}$ on a horizontal mixer, Denley Spiramix 5 (Denley Instruments Ltd, Billingshurst, West Sussex, UK). The suspension was then centrifuged at $830 \mathrm{~g}, 4^{\circ} \mathrm{C}$, for $10 \mathrm{~min}$. An $800 \mu \mathrm{l}$ sample of hexane (upper layer) containing the extracted zeaxanthin was withdrawn and evaporated to dryness at about $45^{\circ} \mathrm{C}$ under a slow stream of $\mathrm{N}_{2}$. The dry residue was temporarily stored in an ice-water-bath and protected from light. The residue was vortexed $(5 \mathrm{~s})$, first with $20 \mu \mathrm{l}$ THF (containing $0 \cdot 1 \%$ (w/v) BHT), followed by the addition of $80 \mu$ l Diluent. The mixture was again well vortexed $(10 \mathrm{~s})$ in order to re-dissolve the residue. These extraction procedures were repeated for the remaining calibrators. For the triacylglycerol-rich fractions, the same procedures mentioned earlier were repeated, except that the entire triacylglycerol-rich fraction harvested from $2 \mathrm{ml}$ plasma was used in place of $100 \mu \mathrm{l}$ diluted zeaxanthin working solution and $500 \mu \mathrm{l}$ Milli-Q water. For the controls, the low or high control $(100 \mu \mathrm{l})$ was used in place of the diluted zeaxanthin working solution. Finally, each extracted calibrator, sample or control $(80 \mu \mathrm{l})$ was injected into the HPLC system.

The HPLC chromatography system used included an Alliance 2695 Separations Module with temperature-controlled column chamber and autosampler (Waters, Milford, MA, USA), Waters 2996 Photodiode Array Detector and Waters Empower Pro PDA software (version 5.00.00.00), a reversed-phase Waters Symmetry, $\mathrm{C}_{18}$, analytical column $(5 \mu \mathrm{m}, 250 \times$ $4.6 \mathrm{~mm}$ internal diameter; Waters Corp., Milford, MA, USA) and a cartridge guard column (Waters Sentry Guard column with titanium frits, Symmetry, $\mathrm{C}_{18}, 5 \mu \mathrm{m}, 20 \times 3.9 \mathrm{~mm}$ internal diameter, also from Waters Corp.). The mobile phase was $0.1 \%$ (w/v) BHT in acetonitrile, which was filtered and degassed through a Millipore membrane (type GV, pore size $0.22 \mu \mathrm{m}$, Millipore Corp.) before use. The detection was set at $450 \mathrm{~nm}$. The flow rate was time-programmed at two speeds; $1.0 \mathrm{ml} / \mathrm{min}$ for $0-17 \mathrm{~min} ; 2.5 \mathrm{ml} / \mathrm{min}$ for $18-60 \mathrm{~min}$. The columns worked under room temperature but the cooling chamber of the autosampler was set at $4{ }^{\circ} \mathrm{C}$.

Peak areas of zeaxanthin and IS were recorded from each chromatogram. By plotting the area ratio of the peak area of zeaxanthin to that of IS against concentration of calibrator spiked (i.e. zeaxanthin spiked into water), a calibration curve for zeaxanthin could be constructed. The equivalent standard concentration $(\mu \mathrm{mol} / \mathrm{l})$ of zeaxanthin in each sample was calculated by dividing the area ratio (zeaxanthin:IS in the sample) with the slope of the calibration curve. Hence, the zeaxanthin concentration $(\mu \mathrm{mol} / \mathrm{l})$ of the blood sample was deduced by multiplying the equivalent zeaxanthin standard concentration $(\mu \mathrm{mol} / \mathrm{l})$ with the volume $(\mu \mathrm{l})$ of zeaxanthin standard used (which was $100 \mu \mathrm{l}$ ) and divided by the volume $(\mu l)$ of the blood sample used for the triacylglycerol-rich fraction extraction $(2 \mathrm{ml})$.

The linear range was determined by direct injections of standards at various concentrations. Linearity of response was assessed from the coefficient of correlation $(r)$ of the regression line. Seven replicates of a calibrator $(0.053 \mu \mathrm{mol} / \mathrm{l})$ were used to assess the within-day precision. The slopes from 10-consecutive-day assays were used to assess the between-day precision.
Diluted solutions of the standard were injected in sequence of decreasing concentrations to measure the detection limit. The signal:noise ratio was at least 2:1 for the limit. For estimation of recovery, Milli-Q water was spiked with zeaxanthin standard $(100 \mu \mathrm{l} 0.053 \mu \mathrm{mol} / \mathrm{l})$ and the IS working standard solution $(100 \mu \mathrm{l})$, extracted and then assayed ( $n$ 7). By comparing with direct injections of an equivalent amount of pure zeaxanthin standard and the IS solution $(n 7)$, recovery was assessed. All samples for zeaxanthin measurement were protected from light at all times, owing to the light-sensitive nature of zeaxanthin.

\section{Statistical analysis}

A key variable of interest in the present study was the $0-10 \mathrm{~h}$ area under the curve (AUC; $0-10 \mathrm{~h} ; \mathrm{nmol} \times \mathrm{h} / \mathrm{l})$ of zeaxanthin. This was calculated for each subject by using trapezoidal approximation. Both the total AUC and the baselineadjusted AUC (corrected for zeaxanthin detected in the fasting samples) are presented. The maximum concentration and the time to reach maximum concentration were also estimated. The $0-10 \mathrm{~h}$ AUC values for zeaxanthin in the triacylglycerol-rich fraction (expressed as nmol/l plasma) were compared across treatments using ANOVA with Neuman-Keuls multiple comparison post test using GraphPad Prism version 4.0 for Windows (GraphPad Software Inc., San Diego, CA, USA), and $P<0.05$ was considered statistically significant.

\section{Results}

The CV for the within-day and between-day precision for zeaxanthin measurements were, respectively, 2.9 and $4.1 \%$. In regard to the limit of detection, this assay could detect down to an amount of 0.35 pmol zeaxanthin injected (peak area of about $2000 \mu \mathrm{V} \times \mathrm{s}$ or signal:noise ratio of $2: 1$ or greater). This is equivalent to $0 \cdot 11 \mathrm{nmol}$ zeaxanthin/l plasma of $2 \mathrm{ml}$ sample size. The recovery of zeaxanthin when extracted from water was $97 \%$. A representative chromatogram is shown in Fig. 1.

The mean responses to each treatment in terms of AUC 0 $10 \mathrm{~h}$ and maximum concentration values for the twelve subjects are presented in Table 1, and the responses by time and treatment are shown in Fig. 2. It can be seen that the response to treatment $\mathrm{A}$ (the hot milk formulation) was about two to three times higher than the response to both treatments B (warm milk formulation) and C (hot water formulation), both of which were similar to each other. The time to maximum response overall was at $6 \mathrm{~h}$, but this varied slightly between subjects.

Variation in response was quite wide, and four of the subjects (three females and one male) showed a very poor response to zeaxanthin ingestion. Therefore the data were reanalysed excluding these subjects. Excluding the poor responders did not change the ranking of treatment response seen with the twelve subjects $(\mathrm{A}>\mathrm{B}=\mathrm{C})$.

\section{Discussion}

Effective nutritional strategies to promote functional longevity in our ageing communities would have a significant socio-economic impact globally. One strategy may be to increase zeaxanthin intake since it has been suggested that this might lead to 


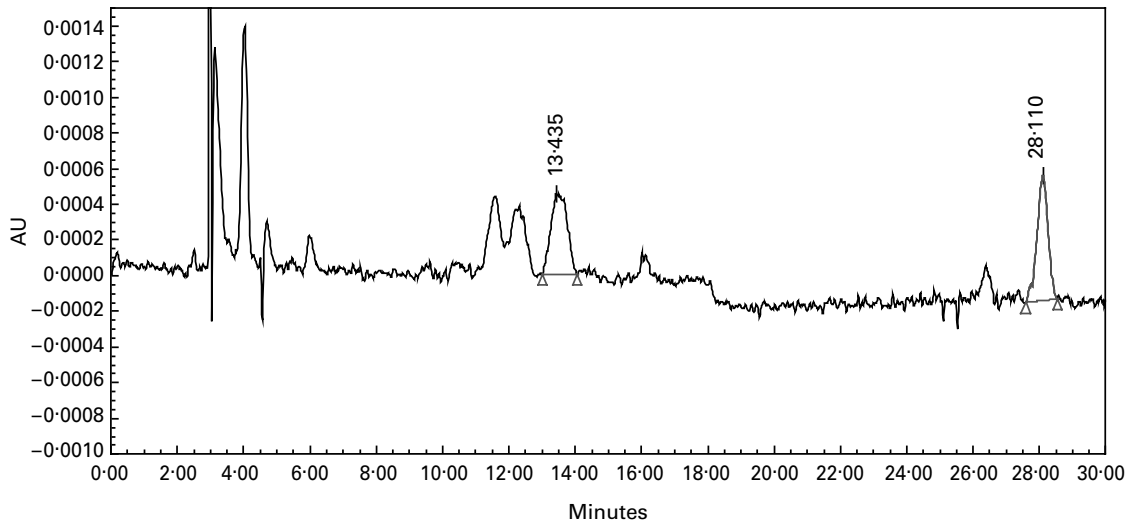

Fig. 1. Representative chromatogram of an extract of the triacylglycerol-rich lipoprotein fraction of blood plasma (blood sample collected after ingestion of zeaxanthin-containing supplement) showing the zeaxanthin peak at $13.435 \mathrm{~min}$ and the internal standard peak at $28.110 \mathrm{~min}$. AU, arbitrary units. For details of subjects and procedures, see p. 155.

preservation of the macular pigment with prevention or delay of age-related maculopathy, to decrease cancer incidence and to reduce early atherosclerosis and ischaemia (Hammond et al. 1997; Mares-perlman et al. 2002). However, the bioavailability of zeaxanthin, and other carotenoids, is low and variable, and is affected by food structure, extraction of nutrients from food, concomitant lipid intake, the type and form of carotenoid, and interaction with other carotenoids or nutrients (Parker et al. 1999; van het Hof et al. 2000). Therefore, care must be taken when designing or choosing carotenoid supplements, and bioavailability is a key factor to consider. 'Traditional' means of food extraction have often employed hot water. However, this

Table 1. Summary of results for twelve subjects treated with three different formulations of wolfberry (Fructus barbarum L.) containing 15 mg zeaxanthin

(Mean values with their standard errors and $95 \%$ confidence intervals)

\begin{tabular}{|c|c|c|c|c|c|c|c|c|c|}
\hline \multirow[b]{2}{*}{ Treatment } & \multicolumn{3}{|c|}{$\mathrm{C}_{\max }(\mathrm{nmol} / \mathrm{l})$} & \multicolumn{3}{|c|}{ AUC $(\mathrm{nmol} \times \mathrm{h} / \mathrm{l})$} & \multicolumn{3}{|c|}{$\begin{array}{l}\text { AUC adjusted for baseline } \\
(\mathrm{nmol} \times \mathrm{h} / \mathrm{l})\end{array}$} \\
\hline & Mean & SEM & $95 \% \mathrm{Cl}$ & Mean & SEM & $95 \% \mathrm{Cl}$ & Mean & SEM & $95 \% \mathrm{Cl}$ \\
\hline A (skimmed milk, $80^{\circ} \mathrm{C}$ formulation) & $1 \cdot 72$ & 0.46 & $0.81,2.62$ & $9 \cdot 73$ & $2 \cdot 45$ & $4 \cdot 33,15 \cdot 14$ & $9 \cdot 73$ & $2 \cdot 45$ & $4 \cdot 33,15 \cdot 14$ \\
\hline $\mathrm{B}$ (skimmed milk, $40^{\circ} \mathrm{C}$ formulation) & 0.75 & 0.21 & $0.33,1.17$ & $4.91^{*}$ & 1.64 & $1 \cdot 69,8 \cdot 12$ & $3 \cdot 24^{\star *}$ & 0.72 & $1 \cdot 66,4.82$ \\
\hline $\mathrm{C}$ (hot water, $80^{\circ} \mathrm{C}$ formulation) & 0.69 & $0 \cdot 21$ & $0 \cdot 28,1 \cdot 10$ & $4 \cdot 39^{*}$ & $1 \cdot 30$ & $1 \cdot 84,6 \cdot 94$ & $3 \cdot 14^{\star *}$ & 1.09 & $0.75,5.54$ \\
\hline
\end{tabular}

$\mathrm{C}_{\max }$, maximum concentration; AUC, area under the curve.

Mean value was significantly different from that for treatment $\mathrm{A}:{ }^{*} P<0.005,{ }^{\star \star} P<0.001$.

For details of subjects and procedures, see p. 155.

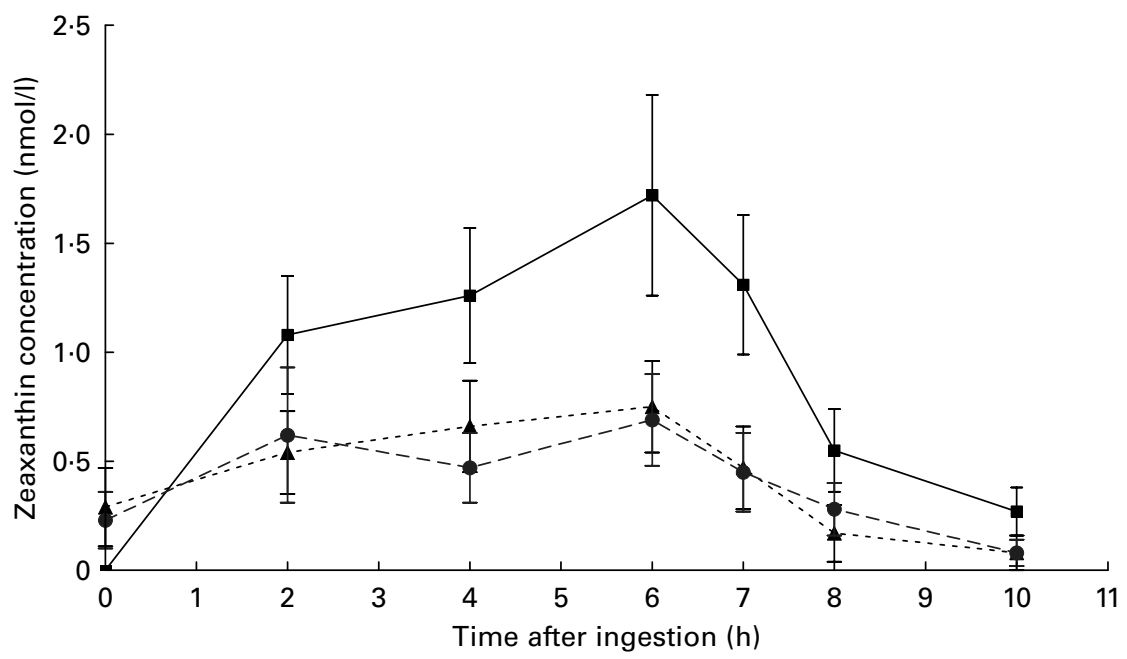

Fig. 2. Zeaxanthin concentration in triacylglycerol-rich lipoprotein fraction of blood plasma collected before and up to $10 \mathrm{~h}$ post-ingestion of $15 \mathrm{mg}$ zeaxanthin in each of three different formulations as follows: A (hot skimmed milk formulation; $\mathbf{\square}$ ); B (warm skimmed milk formulation; $\mathbf{\Lambda}$ ); C (hot water formulation; $\bullet$ ). Results are means of twelve subjects, with standard errors of the mean represented by vertical bars. For details of subjects and procedures, see p. 155. 
may leave bioactive components unextracted. Whey protein formulation has been reported to improve bioavailability of lycopene (Richelle et al. 2002). The present study has shown the effect of formulation and processing of a carotenoid-rich food on zeaxanthin bioavailability.

It was noticeable that the hot and warm milk-based formulations were, respectively, orange and red in colour. This difference may reflect a different interaction between zeaxanthin and other biopolymers. In practice we conclude that in the presence of milk proteins, the higher temperature of processing enhances zeaxanthin bioavailability of wolfberry, presumably by improving its incorporation into mixed micelles, uptake by enterocytes and subsequent release in triacylglycerol-rich lipoproteins. The exact mechanism for the enhancement of bioavailability is still unclear and is the object of on-going research. However, it is worth noting that the enhanced bioavailability was not due to additional fat ingestion, as skimmed milk was used in both milk-based formulations.

Previously published human studies that have investigated plasma zeaxanthin to single-dose ingestion or supplementation have used eggs (Handelman et al. 1999), purified non-esterified zeaxanthin (Hartmann et al. 2004), zeaxanthin extracted from wolfberry in esterified and non-esterified forms (Breithaupt et al. 2004), and whole wolfberries (Cheng et al. 2005). Ingestion of eggs has the disadvantage of increasing LDL-cholesterol, with a concomitant increase in CHD risk (Verschuren et al. 1995), and attention is worth focusing on other natural sources of zeaxanthin. However, there is only one previous study (Pérez-Gálvez et al. 2003) that has investigated the bioavailability of zeaxanthin in terms of the triacylglycerol-rich lipoprotein response. In an uncontrolled study of nine subjects, PérezGálvez et al. (2003) studied chylomicron zeaxanthin content after ingestion of paprika oleoresin containing $5.3 \mathrm{mg}$ zeaxanthin (and ingested along with bread and $5 \mathrm{~g}$ oil) in the esterified form. Results showed that response peaked at $6 \mathrm{~h}$ post-ingestion, as was found in the present study. The mean maximum chylomicron zeaxanthin concentration was 5.73 (SEM 1.14) nmol/l plasma, and the 0-12 h AUC was 32.3 (SEM 1.12) $\mathrm{nmol} \times \mathrm{h} / \mathrm{l}$. The two other acute-response studies (Breithaupt et al. 2004; Hartmann et al. 2004) monitored whole plasma response, and comparison with response in triacylglycerol-rich fraction of plasma is not meaningful.

Populations consist of low to high carotenoid absorbers, and as a result all studies performed to date, including the present one, have shown a very large inter-individual variation in response. In the present study, four subjects gave a very poor or even undetectable response to zeaxanthin ingestion. However, the rank order of zeaxanthin bioavailability from the different treatments was the same whether or not this was taken into account. This large inter-individual variability might be explained by pre-existing zeaxanthin status or by other factors such as expression and activity of transporters. Indeed, it has been recently demonstrated in Caco-2 TC-7 cells (Reboul et al. 2005) that lutein is not only absorbed by passive diffusion but also by facilitated transport processes. These transporters, which are also implicated in the transport of other lipid-soluble materials, are known to be present in various polymorphic forms in man (Hubacek et al. 2004; Miwa et al. 2005; Puddu et al. 2005; Woll et al. 2005). This may affect absorption efficiencies, probably explaining the highly variable inter-individual absorption seen. Further work is needed in this area of nutrigenomics.

In summary, the new data presented here show that the bioavailability of zeaxanthin in a natural product (wolfberry) can be enhanced three-fold by homogenisation of the berries in hot skimmed milk. This is of relevance to nutrition and to human health because it is suggested that increased dietary intake of zeaxanthin may help maintain the macular pigment and, thereby, lower the risk of AMD, an increasingly common, irreversible and largely untreatable cause of visual disability. In this regard, a food supplement from a natural source that has an enhanced zeaxanthin bioavailability is of interest and potential benefit. The question of the efficacy of increased zeaxanthin intake in terms of macular pigment density and AMD prevention is an interesting and potentially valuable area of research that can only be answered by long-term supplementation studies using zeaxanthin-containing supplements of enhanced bioavailability, such as the one described in the present study.

\section{Acknowledgements}

The present study was supported by Nestlé R\&D Center, Shanghai Ltd (Shanghai, China), Nestlé Research Center (Lausanne, Switzerland) and by The Hong Kong Polytechnic University. The authors are grateful to Dr Szeto Yim-tong, Dr Sissi Wachtel-Galor and Ms Choi Siu-wai of the Antioxidant Research Group at The Hong Kong Polytechnic University for their skilled assistance in the present study. Thanks also go to Nicole Fang (Nestlé R \& D Center, Shanghai Ltd), Wen Sze Lien (Nestlé R\&D Center, Singapore), Laurent Crosset-Perrotin, Alain Fracheboud, Raymond Bertholet, Pierre Ducret, Gillian Anantharaman, Liliane Meyer and Christian Perrin (Nestlé Research Center, Lausanne, Switzerland) for excellent technical assistance. We are grateful also to the volunteers who participated in the present study.

\section{References}

Aebischer CP, Schierle J \& Schüep W (1999) Simultaneous determination of retinol, tocopherols, carotene, lycopene, and xanthophylls in plasma by means of reversed-phase high-performance liquid chromatography. Methods Enzymol 299, 348-362.

Bai S (1999) Research on Ningxia Wolfberry (Lycium barbarum), vols. 1 and 2. Ningxia, China: People's Publishing House.

Bartlett H \& Eperjesi F (2003) Age-related macular degeneration and nutritional supplementation: a review of randomized controlled trials. Ophthal Physiol Opt 23, 383-399.

Beatty S, Boulton M, Henson D, Koh HH \& Murray IJ (1999) Macular pigment and age related macular degeneration. Br J Ophthalmol 83, $867-877$.

Beatty S, Koh H, Henson D \& Boulton M (2000) The role of oxidative stress in the pathogenesis of age-related macular. Surv Ophthalmol 45, 115-134.

Benzie IFF (2003) Evolution of dietary antioxidants. J Compar Biochem Physiol 136, 113-126.

Bone RA, Landrum JT, Dixon Z, Chen Y \& Llerena CM (2000) Lutein and zeaxanthin in the eyes, serum and diet of human subjects. Exp Eye Res 71, 239-245.

Bone RA, Landrum JT, Guerra LH \& Ruiz CA (2003) Lutein and zeaxanthin dietary supplements raise macular pigment density and serum concentrations of these carotenoids in humans. J Nutr 133, 992-998. 
Breithaupt DE, Weller P, Wolters M \& Hahn A (2004) Comparison of plasma responses in human subjects after the ingestion of $3 \mathrm{R}, 3 \mathrm{R}^{\prime}$-zeaxanthin dipalmitate from wolfberry (Lycium barbarum) and non-esterified $3 \mathrm{R}, 3 \mathrm{R}^{\prime}$-zeaxanthin using chiral high-performance liquid chromatography. Br J Nutr 91, 707-713.

Cheng CY, Chung WY, Szeto YT \& Benzie IFF (2005) Fasting plasma zeaxanthin response to Fructus barbarum L. (wolfberry; Kei Tze) in a food-based human supplementation trial. Br J Nutr 93, 123-130.

Curcio CA, Owsley C \& Jackson GR (2000) Spare the rods, save the cones in aging and age-related maculopathy. Invest Ophthalmol Vis Sci 41, 2015-2018.

Dwyer JH, Paul-Labrador MJ, Fan J, Shircore AM, Merz CNB \& Dwyer KM (2004) Progression of carotid intima-media thickness and plasma antioxidants: The Los Angeles Atherosclerosis Study. Arterioscler Thromb Vasc Biol 24, 313-319.

Gonzalez S, Astner S, An W, Goukassian D \& Pathak MA (2003) Dietary lutein/zeaxanthin decreases ultraviolet B-induced epidermal hyperproliferation and acute inflammation in hairless mice. $J$ Invest Dermatol 121, 399-405.

Hammond BR Jr, Johnson EJ, Russell RM, Krinsky NI, Yeum KJ, Edwards RB \& Snodderly DM (1997) Dietary modification of human macular pigment. Invest Opthalmol Vis Sci 38, $1795-1801$.

Handelman GJ, Dratz EA, Reay CC \& van Kuijk JG (1988) Carotenoids in the human macula and whole retina. Invest Ophthalmol Vis Sci 29, 850-855.

Handlelman GJ, Nightingale ZD, Lichenstein AH, Scaefer EJ \& Blumberg JB (1999) Lutein and zeaxanthin in plasma after dietary supplementation with egg yolk. Am J Clin Nutr 70, 247-251.

Hartmann D, Thurmann PA, Spitzer V, Schalch W, Manner B \& Cohn W (2004) Plasma kinetics of zeaxanthin and 3 '-dehydrolutein after multiple oral doses of synthetic zeaxanthin. Am J Clin Nutr 79, 410-417.

Hubacek JA, Berge KE, Stefkova J, Pitha J, Skodova Z, Lanska V \& Poledne R (2004) Polymorphisms in ABCG5 and ABCG8 transporters and plasma cholesterol levels. Physiol Res 53, 395-401.

Humphries JA \& Khachik F (2003) Distribution of lutein, zeaxanthin, and related geometrical isomers in fruit, vegetables, wheat and pasta products. J Agric Food Chem 51, 1322-1327.

Hyman L \& Neborsky R (2002) Risk factors for age-related macular degeneration: an update. Curr Opin Ophthalmol 13, 171-175.

Krinsky NI, Landrum JT \& Bone RA (2003) Biologic mechanisms of the protective role of lutein and zeaxanthin in the eye. Ann Rev Nutr 23, 171-201.

Lam KW \& But P (1999) The content of zeaxanthin in Gou Qi Zi, a potential health benefit to improve visual acuity. Food Chem 67, $173-176$.

Landrum JT \& Bone RA (2001) Lutein, zeaxanthin, and the macular pigment. Arch Biochem Biophys 385, 28-40.

Landrum JT, Bone RA, Joa H, Joa H, Kilburn MD, Moore LL \& Sprague KE (1997) A one year study of the macular pigment: the effect of 140 days of a lutein supplement. Exp Eye Res 65, 57-62.

Landrum JT, Bone RA, Moore LL \& Gomez CM (1999) Analysis of zeaxanthin distribution within individual human retinas. Methods Enzymol 299, 457-467.

Le Marchand L, Hankin JH, Kolonel LN, Beecher GR, Wilkens LR \& Zhao LP (1993) Intake of specific carotenoids and lung cancer risk. Cancer Epidemiol Biomarkers Prev 2, 183-187.

Leung IYF, Tso MOM, Li WWY \& Lam TT (2001) Absorption and tissue distribution of zeaxanthin and lutein in rhesus monkeys after taking Fructus lycii (Gou Qi Zi) extract. Invest Ophthalmol Vis Sci 42, 466-471.

Mares-Perlman JA, Millen AE, Ficek TL \& Hankinson SE (2002) The body of evidence to support a protective role for lutein and zeaxanthin in delaying chronic disease: an overview. J Nutr 132, $518 \mathrm{~S}-524 \mathrm{~S}$.
Miwa K, Inazu A, Kobayashi J, Higashikata T, Nohara A, Kawashiri M, Katsuda S, Takata M, Koizumi J \& Mabuchi H (2005) ATPbinding cassette transporter G8 M429V polymorphism as a novel genetic marker of higher cholesterol absorption in hypercholesterolaemic Japanese subjects. Clin Sci 109, 183-188.

Moeller SM, Jacques PF \& Blumberg JB (2000) The potential role of dietary xanthophylls in cataract and age-related macular degeneration. J Am Coll Nutr 19, Suppl. 5, 522S-527S.

Mozaffarieh M, Sacu S \& Wedrich A (2003) The role of the carotenoids, lutein and zeaxanthin, in protecting against age-related macular degeneration: a review based on controversial evidence. Nutr $J$ 2, 20-31.

Olmedilla B, Granado F, Bianco I, Vaquere M \& Cajigal C (2001) Lutein in patients with cataracts and age-related macular degeneration: a long-term supplementation study. J Sci Food Agric 81, 904-909.

Parker RS, Swanson JE, You CS, Edwards AJ \& Huang T (1999) Bioavailability of carotenoid in human subjects. Proc Nutr Soc 58, $155-162$.

Pérez-Gálvez A, Martin HD, Sies H \& Stahl W (2003) Incorporation of carotenoids from paprika oleoresin into human chylomicrons. $\mathrm{Br}$ J Nutr 89, 787-793.

Polidori MC, Cherubini A, Stahl W, Senin U, Sies H \& Mecocci P (2002) Plasma carotenoid and malondialdehyde levels in ischemic stroke patients: relationship to early outcome. Free Radic Res 36, $265-268$.

Puddu P, Cravero E, Puddu GM \& Muscari A (2005) Genes and atherosclerosis: at the origin of the predisposition. Int $J$ Clin Pract 59, 462-472.

Reboul E, Abou L, Mikail C, Gghiringhelli O, Andre M, Portugal H, Jourdheuil-Rahmani D, Amiot MJ, Lairou D \& Borel P (2005) Lutein transport by Caco-2 TC-7 cells occurs partly by a facilitated process involving the scavenger receptor class B type I (SR-BI). Biochem J 387, 455-461.

Richelle M, Bortlik K, Liardet S, Hager C, Lambelet P, Baur M, Applegate LA \& Offord EA (2002) A food-based formulation provides lycopene with the same bioavailability to humans as that from tomato paste. J Nutr 132, 404-408.

Rose RC, Richer SP \& Bode AM (1998) Ocular oxidants and antioxidant protection. PSEBM 217, 397-407.

Slattery ML, Benson J, Curtin K, Ma K, Shaeffer D \& Potte RJD (2000) Carotenoids and colon cancer. Am J Clin Nutr 71, 575-582.

Sommerburg O, Keunen JE, Bird AC \& van Kuijk FJ (1998) Fruits and vegetables that are sources for lutein and zeaxanthin: the macular pigment in human eyes. Br J Ophthalmol 82, 907-910.

Stokkermans TJW (2000) Treatment of age-related macular degeneration. Clin Eye Vis Care 12, 15-35.

Terpstra AHM (1985) Isolation of serum chylomicrons prior to density gradient ultracentrifugation of other serum lipoprotein classes. Anal Biochem 150, 221-227.

van het Hof KH, West CE, Weststrate JA \& Hautvast JGAJ (2000) Dietary factors that affect the bioavailability of carotenoids. $J$ Nutr 130, 503-506.

Verschuren WM, Jacobs DR, Bloemberg BP, et al. (1995) Serum total cholesterol and long term coronary heart disease mortality in different cultures. Twenty-five-year follow-up of the Seven Countries Study. JAMA 274, 131-136.

Weller P \& Breithaupt DE (2003) Identification and quatification of zeaxanthin esters in plants using liquid chromatography-mass spectrometry. J Agric Food Chem 51, 7044-7049.

Woll PS, Hanson NQ, Arends VL \& Tsai MY (2005) Effect of two common polymorphisms in the ATP binding cassette transporter A1 gene on HDL-cholesterol concentration. Clin Chem 51, 907-909.

Zhou L, Leung I, Tso MOM \& Lam KW (1999) The identification of dipalmityl zeaxanthin as the major carotenoid in Gou Qi Zi by high pressure liquid chromatography and mass spectrometry. J Ocul Pharmacol Ther 15, 557-565. 